\title{
A Research of Ecological Design of Suzhou Urban Green Space Landscape
}

\author{
Huirong Zhao ${ }^{1, \text { a }}$ \\ ${ }^{1}$ Department of Environment and Art, Suzhou Art \& Design Technology Institute \\ ${ }^{a}$ email
}

Keywords: Ecological Design, Suzhou Urban Green Space

\begin{abstract}
Let the urban green space alive," Suzhou Garden Design Institute is currently being adjusted, "Suzhou urban green space system planning", with this sentence a new planning ideas. The latest green overall layout has been determined through the center of protected areas, perimeter protection and ecological corridors, and build a system of ecological green space in the city
\end{abstract}

\section{Investigation and analysis of systematic planning of Suzhou urban green space landscape and current ecological statu}

According to the urban master planning of Suzhou (2006-2020) outline, the latest planning objective is: implementing the urban development goal proposed in this planning "Green Hill and Clean Water, New Paradise", realizing the urban landscape features of "Green Hill and Clean Water" and "Yangtze River Delta".

The central urban area green space system framework proposed in the planning includes suburb green space and urban green space and forms the structure of "two belts, three rings and five wedges" as well as the landscape pattern of "green mountains entering the city, green surrounding the city, water chains weaving the city and beautiful gardens decorating the city". The systematic planning ideology of this green space landscape system advocates, carries forward and strengthens green space landscape features with the characteristic water culture of Suzhou, the combination of dots, lines and faces, the construction of green gallery system as well as healthy and orderly green ecological network.

Analysis of the ecological recent development of Suzhou urban green space. Suzhou government has made great efforts in the construction of urban green land, and its resolution in protection and reconstruction of urban ecology is determined. However, from the recent development of urban green space ecological landscape, it is not hard to find out the following problems:

According to the materials and data of Suzhou urban ecological landscape pattern from landscape ecology, the most significant characteristics of the landscape pattern of Suzhou in recent decades are the miniaturization of average plaque area and the rise of fragmentation of landscape patch. The overall shape of urban landscape pattern is becoming increasingly complicated. Major reason leading to this is that human beings' various construction activities are becoming increasingly fierce; urban green space, farmland and other landscape types are embezzled or divided by constructions or other types of land; their previous patterns are divided increasingly more complicated and fragmented, so the integral shape of the landscape also becomes more complicated.

Problems and misunderstandings of Suzhou urban green space landscape ecological design. At present, Suzhou has entered ecological construction period and partial ecological profit period. Ecologicalization is still at the beginning period. Some "pseudo-ecological landscapes" that violate 
natural rules and exceed ecological bearing capacity and environment capacity construction come out. The author summarizes problems found during the investigation and analysis as follows:

Misunderstandings in ecological design. The misunderstandings are mainly concentrated in the layer of planning and decision. Some decision-makers believe that "ecological design" is nothing but afforestation, planning trees, building "ecological parks" and "livable city"; under conditions of low landscape recognition ability or low appreciation standards, while some follow the general trend blindly, pursing "face-saving projects" such as "square fever", "lawn fever", "waterscape fever" and so on that violate ecological construction; while some are inclined to build "ecological city" with high cost. These misunderstandings also result from the rare participation of ecological experts and lack of professional guidance during green space landscape development planning. Therefore, during planning and designing stage, some decisions went against the original intention of ecological civilization construction.

Improvement of the overall standard of landscape design industry. The integrity of landscape design major is strong. It not only requires engineering technology, but also art design and aesthetics. In the meantime, it should give consideration to responsibility of ecology, environmental protection and beautification. Shi Kuang, director of Suzhou Industrial Park and well-known senior architect, said that the artistic standard of Suzhou in environmental construction was high and advanced; however, most of the design was overseas and very few local designers participated in it; it was mainly because it started quite late and the standard was low. He felt it quite a pity that landscape design talents were in shortage.

The design did not observe site characteristics; the style became apparent and lacked local features. After the author visited and investigated several urban green spaces of Suzhou, he found that the design of some green space landscape pursued some fashion elements blindly; the landscape was excessively "stylish" and the design was "superficial". They tried to be attractive but were hard to impress people. Some people call it a wet land if there were some rocks, marsh plant and helophyte at the waterside of the green space landscape. Some places are called ecological gardens if trees and bushes are planted and there are more plant layers. These people did not know that design and construction of various wetland landscape and ecological landscape needed the cooperation of people from multiple disciplines. These green space landscapes cannot coordinate and blend with surrounding environment and with the improvement of people' s ever increasing recognition and appreciation standard, they are easily rejected by the public and the society. These landscape elements might be re-constructed or re-modified after a short life cycle, which is bound to bring huge waste for environmental construction and ecological civilization construction.

Insufficiencies of high-tech technology application. As to urban green space landscape ecological design, the application of high-tech is mainly in three aspects, i.e., new materials, new energy and biotechnology. High-tech is the edge tool of conquering some construction difficulties and its grasping and application need some rigorous technical support.

After investigations, it is found out that the application of high-tech is not widespread in Suzhou urban green space landscape ecological design. On the one hand, it is related to the backward technical development and the disadvantaged promotion of new energy and new materials; on the other hand, the design methods are quite single and the design standard is backward. Therefore, it is clear that Suzhou urban green space landscapes have insufficient creation in techniques and methods of ecological design. Therefore, it is difficult to make breakthroughs in local characteristics and styles of landscape effect. 


\section{Analysis of methods and techniques of urban green space landscape ecological design}

The most basic requirement of constructing ecological city is to have professional technical support. Researches and practices of technology subjects are important means of building ecological civilization cities. The author started from the perspective of studying the techniques of ecological design and explained the specific technical problems of landscape ecological design so that people could have new understandings of the design and construction of ecological landscape.

Ecological landscape planning method of combining ecological principles and landscape architecture planning. Macroscopic green space landscape ecological planning design is the beginning of the project. Accurate and reliable ecological planning ideology and principles and methods should be grasped so that accurate planning is prior to exquisite design. In this way, design can be carried out with purpose. The overall planning design stages of urban green space landscape ecological design should include:

Ecological design should start from understanding and analyzing site environment. Comprehensive and scientific analysis and researches should be conducted to the surrounding areas, various ecological factors and species so as to reduce damage on the previous natural environment through reasonable planning and design and protect the previous fine ecological system.

Recovery and promotion design means ecological landscape recovery and compensation on the damaged and destructed environment through advanced design philosophy and technical methods. This requires understanding and respect to natural ethics in design practice so as to explore ecological development mode suitable to the actual situations.

The purpose of ecological compensation is to protect and utilize ecological system service sustainably, maintain, improve and promote the service function of ecological system and further improve the ecological environment quality of the damaged areas, or create new areas with similar environment quality and ecological functions so as to promote harmonious relationship between human beings and nature. The design philosophy of "compensation and adaptation" includes advocating design personnel to establish new material choosing philosophy. On the one hand, the utilizability of the materials in the previous environment should be taken into consideration; on the other hand, it is required to choose sustainable equipment and design further. The utility value of discarded land and materials should be found. The previous vegetation, soil and masonry should re-serve new functions through updating design, which saves resources and energy consumption greatly and continues context of the site.

Middle and micro-scale landscape ecological design technique. The ecological design techniques discussed here mainly refer to restoration and control techniques that combine the previous site resources to realize the restoration or regeneration through some modern techniques and means and combine the previous site resources so as to reach the harmonious development between human beings and nature on the basis of observing ecology principles and utilizing systematic scientific methods. Landscape ecology restoration techniques are mainly divided into three types, i.e., landform and topography reconstruction technology, vegetation recovery and reestablishment technique and water body comprehensive improvement technique.

Generally speaking, landscape project construction must remold the initial landforms through earthwork, either land grading, heaping mountains and building water or ditching, laying pipes, channeling and paving. Terrain transformation is the primary issue in landscape design. At present, methods of landform transformation ecological system design mainly includes mechanical fixing terrain, module surface, and surface overturn, etc. 
The initial landform should be made full use of in green space landscape terrain design, which saves craftsmanship and capital expenditure, reduces energy consumption and volume of earthwork and maintains the ecological environment of the previous site to the maximum. Under conditions that transforming the terrain according to design, the design should strive to achieve balance of earth volume in the site, reduce carrying, or shorten earth adaptation shipment distance as much as possible. The philosophy of ecological design advocates minimum design of volume of earthwork under the premise of sufficient expression of design intention.

Vegetation ecological restoration technology. In green space landscape ecological design, plants play important roles in environment science, ecological science and environment aesthetics. Specific ecological design technique methods are as follows:

The choice of plant landscape varieties of trees should observe principles of overall planning of the site, matching species with the site and diversity; in the meantime, utilization and development of new species, molding of landscape space, quarantine, requirements on terrain and water body as well as other resource elements should be considered.

Colorful plant species should be matched greatly and flexibly. Design methods such as time series and space construction should be utilized and verification should be achieved through environment improvement and artistic conception reflection. According to three-dimensional quantity and data table of annual environmental benefit quantity data of relative materials. Carbon fixation and oxygen release ability: evergreen shrub $\rangle$ deciduous tree $\rangle$ aiphyllium $\rangle$ deciduous shrub. Maximum benefits come from comprehensive green vegetation. Therefore, we emphasize that the richness of plant layers in landscape is very important.

As the saying goes, "afforestation relies more on maintenance than planting". Therefore, besides type collocation, maintenance cost and effect in later stage should also be considered in the design, and it is one of the ways for ecological benefit maximization.

\section{Water body comprehensive improvement design technique}

When designing urban green space landscape waterscape design, understanding and collection of the current situation in urban river system and river system planning should be conducted. Suzhou is national civilized waterside town, and it was called "Oriental Venice". However, this title has rarely been used in recent years. As to the reasons, the author believes that firstly, water pollution is serious; secondly, waterscape effects are not good enough. Therefore, as to how to do the waterscape ecological design of Suzhou urban green space, there are the following methods:

Ecological comprehensive treatment technology of water areas. River networks in Suzhou are densely covered. Therefore, bringing in the philosophy of ecological treatment and green space construction can recover the virtuous cycle of aquatic ecosystem effectively. Both sides of River Bin should consider the form of afforestation gardens, banding roadside green space. On the one hand, it can satisfy people' s relaxation activities; on the other hand, it can obstruct the direct discharging surface runoff and municipal refuse; natural revetment can be constructed selectively, aquatic plant, bio-floating bed and other means can be used to improve water purification ability; artificial wetland system can be established and ecological slope protection technology can be brought in, which are all good ecological waterscape design methods and are worthy of generalizing.

Biotechnology improves self-purifying capacity of water body. Traditional water pollution treatment methods include cleaning impurities or flotage in water in manual or physical ways, 
utilizing chemical algicide to clean rich oxide alga substance. All these methods are time-consuming and money-consuming and chemical substances would cause secondary pollution. Water pollution treatment of ecological design is mainly realized by energy flow and circulation of materials in ecological system, i.e., biotechnological means. For example, utilization of bio-enzyme and advanced microorganism cultures can improve the self-cleaning capacity of water greatly. In addition, utilizing animals and plants in the water can help mold rich ecological system, strengthen energy flow and circulation of materials, which can also realize water-purification.

Establishing low-energy waterscape of new forms. Music fountains, water curtains, fountains and other waterscape forms are not rare in Suzhou. Though the effects are splendid, environmental issues such as high energy consumption, high discharge, expensive maintenance fees are also attached, and they are not suitable to be constructed in large number. The more widespread way is to develop new form of waterscape under the premise of low carbon and environmental protection.

Attention and technology application of "sponge city". Urban green space is a "cavernous body" in "sponge city". The water environment, water ecological problems and water landscape elements in its planning, design and construction are all included in the problems that need to be dealt with of the "sponge city". The technology level of "sponge city" includes three layers: firstly, natural ecological design technology. Secondly, ancient water adaptive technique heritage; thirdly, contemporary advanced technique of Western rainfall flood management, including LID technology, water sensitive city design, etc.

\section{Landscape ecological design application of new materials and new energy techniques}

The application of new materials, new energies and biotechnology in urban green space landscape ecological design can help landscape design develop towards a more reasonable, scientific and ecological direction. Among it, hydroenergy, wind energy and light energy have been developed and applied.

New material technology can bring visual aesthetics and comfort in touch through texture, forms and color of the materials; in the meantime, new materials play important roles in building ecological landscape. New materials can be divided into four types: inorganic nonmetallic materials, metallic materials, organic polymer materials and advanced composites. According to material property, it can be divided into structural materials and functional materials. Structural materials have special requirements on the structural property and mechanics property of the materials, and they should satisfy performances of high strength, high hardness, high rigidity, thermostability, wear-resisting, anti-corrosion, radiation proof and other performances; functional materials make use of the physical effects of the materials to satisfy the needed functions, such as light-sensitive materials, semiconductor materials, magnetic materials, stealth materials, etc.

\section{Conclusion}

Some people regard urban green space landscape as an economic object, a treasure or commodity, or investment subject. However, some people treat it as a dynamic system full of life, a place to live in, a habitat of animals and plants, and a site with history, culture and aesthetic values. Therefore, it should be planned, protected, designed, managed and protected reasonably. The author agrees to the latter point, and he hopes that through discussion of the above content, people can analyze the urban green space landscape situation from ecological perspective of Suzhou and discuss the theories and 
methods of urban green space landscape design through technical layer of ecological design.

\section{References}

[1] Jia Xinzhang, Li Jingyuan. Green Industry, Vol. 6 (2004) No 53, p.25-26

[2] Peng Sue, Wang Yunhui, Wang Qunyong. Ecologic System Design, Vol. 12 (2005) No 27, p.74-76

[3] Qian Xiyuan, Jing Jianfen, Hou XuSiem. Structure Engineering, Vol. 30 (2004) No 19, p.144-145

[4] Wang Kuailiang. Mining machinery, Vol. 29 (2008) No 27, p.21-23

[5] Zhang Gongxu, Sun Jing. New Quality Management, Vol. 8 (2003) No 27, p.57-60 